Check for updates

1 London School of Hygiene and Tropical Medicine, Department of Health Services Research and Policy, London, UK

2 Nuffield Trust, London, UK Correspondence to: L M Pettigrew Cite this as: BMJ 2020;370:m3353 http://dx.doi.org/10.1136/bmj.m3353 Published: 03 September 2020

\section{Primary care networks: the impact of covid-19 and the challenges ahead}

\author{
The pressures of the pandemic threaten network development
}

\author{
Luisa M Pettigrew, ${ }^{1}$ Stephanie Kumpunen, ${ }^{2}$ Nicholas Mays ${ }^{1}$
}

In 2019, general practices in England came together to form 1259 primary care networks. NHS England sees these networks as a route to improving collaboration between general practice and other community based providers, expanding the multidisciplinary workforce, and becoming the building blocks for integrated care systems as part of the NHS long term plan. ${ }^{1}$ Despite disquiet about whether the funding offered for the expected workload is adequate and concerns that participating in the networks threatens GPs' independent contractor status, nearly all practices $(98 \%)$ renewed their contract for a second year alongside their practice based contract. ${ }^{2-4}$

\section{Challenges}

Covid-19 has now brought challenges that threaten the ability of the fledgling networks to deliver on expectations. The burden of ill health not related to covid-19 has grown as routine services were suspended at the peak of the pandemic and people have avoided general practices, hospital outpatients, and accident and emergency departments. ${ }^{5}$

As the NHS works out how to restart routine services with the ongoing risk of outbreaks, primary care will be put under additional strain by delayed presentations, investigations, and treatment; poorly controlled long term conditions; a rise in mental illness; the need to deliver the largest flu vaccination campaign to date; the effects of "long covid"; and widened socioeconomic inequalities due to covid-19 and the associated response. ${ }^{67}$ General practices, particularly smaller ones, will face workforce shortages as staff have to shield, intermittently self-isolate, or fall sick. ${ }^{8}$ The shift in general practice to total triage and remote consulting may help service recovery, but remote consultations can pose their own risks to patient care and, where needed, any face-to-face care will be slowed by tight infection control measures in often ill-suited premises.

Despite these challenges, primary care networks could still thrive-strengthening practices' resilience by sharing staff and premises, enabling local systems to integrate through closer collaboration with community and secondary care providers, and working together to tackle inequalities and improve quality of care. However, most networks are still fragile, and the ongoing pressures of the pandemic pose a threat.

This year, primary care networks are expected to work on projects including implementing structured medication reviews, improved cancer diagnosis, enhanced care in care homes, expanding the multidisciplinary workforce, and offering extended hours appointments, as well as meeting targets related to flu vaccinations, learning disabilities, and social prescribing. To deliver these services successfully, the networks, as non-hierarchical organisations, principally rely on good relations, trust, and reciprocity. $9^{-11}$ Building these relations requires time and goodwill, which may be in short supply as practices struggle to meet their own patients' needs, and tensions will emerge if network resources need to be channelled into less resilient practices.

\section{Uncertainties}

In view of these challenges NHS England has sensibly advised that the contracts of primary care networks should be managed supportively and collaboratively. ${ }^{12}$ Most start dates for network service requirements have been postponed until October in response to covid-19, and performance measures seem to leave room for primary care networks to manoeuvre. ${ }^{2}$ Still, GPs remain uneasy about their ability to meet expectations, and uncertainty prevails about how local commissioners will respond.

One particular problem is enhanced care in care homes, where investment from local authorities and clinical commissioning groups has historically been variable and often insufficient. ${ }^{13} \mathrm{GPs}$ have argued that the "care home premium" of $€_{120}\left(€_{130}\right.$; \$160) a year for each bed is inadequate to provide weekly multidisciplinary care home rounds and comprehensive care planning. ${ }^{14}$

Questions also remain regarding the ability of primary care networks to recruit staff to additional roles. Given national shortages of GPs and nurses, these new roles-including social prescribers, pharmacists, physician associates, and physiotherapists-are largely welcome. But where they will come from, the knock-on effect on the rest of the health system, how they will be trained, and their effect on continuity of care in general practice remain unclear. ${ }^{415}$

\section{Long term undertaking}

Evidence from other attempts at large scale interorganisational integration suggests it will take years, if not decades, for general practices to work out how best to relate to one another and other local stakeholders. ${ }^{10}$ Pre-existing large scale general practice provider organisations-such as GP federations-and new organisations such as training hubs are still trying to work out their role in relation to primary care networks. ${ }^{16}$ To add to the challenge, on 1 April 2020 clinical commissioning groups across England merged aiming to create larger integrated care systems. ${ }^{17}$ 
Navigating this shifting external NHS landscape, alongside managing relations within the networks, will be no mean feat for the networks' part time clinical directors, many of whom are in their first clinical leadership role. ${ }^{15}{ }^{18}$ If primary care networks are to become effective vehicles for better patient care, all stakeholders therefore need to continue to be wary of setting them overambitious expectations in their early years, particularly during a pandemic, and create supportive environments where relationships in the networks can mature.

Competing interests: We have read and understood BMJ policy on declaration of interests and declare that LP is a primary care network clinical director and a general practitioner.

Provenance and peer review: Not commissioned; externally peer reviewed.

With thanks to Stewart Block, co-chair (volunteer) of Community Barnet Primary Health Group, for providing input from a patient's perspective. LP is funded by a National Institute of Health Research (NIHR) doctoral research fellowship. The views expressed are not necessarily those of the NHS, the NIHR, or Department of Health and Social Care.

1 NHS England. The NHS Long Term Plan. NHS England, 2019

2 NHS England. Network contract directed enhanced service contract specification 2020/21. PCN requirements and entitlements. NHS England, 2020.

3 NHS England. NHS England announces overwhelming take up of new primary care network contract. Press release 12 Jun 2020. https://www.england.nhs.uk/2020/06/nhs-england-announces-overwhelming-take-up-of-new-primary-care-network-contract/

4 Special Conference of England LMC Representatives. Agenda 2020. https://www.bma.org.uk/media/2121/bma-special-conference-of-english-Imcs-march-2020.pdf

5 Office for National Statistics. Analysis of death registrations not involving coronavirus (covid-19-19), England and Wales: 28 December 2019 to 1 May 2020. 2020 June. Report No.

6 Greater London Authority. Socio-economic impact of COVID-19. 14 August 2020. https://data.gov.uk/dataset/b49458f4-38f3-4384-a9e3-89b606906845/socio-economic-impact-of-covid19

7 Greenhalgh T, Knight M, A'Court C, Buxton M, Husain L. Management of post-acute covid-19 in primary care. BMJ 2020;370:m3026. doi: 10.1136/bmj.m3026 pmid: 32784198

8 Fisher R, Asaria M. How might COVID-19 affect the number of GPS available to see patients in England? Health Foundation, 2020.

9 Brown BB, Patel C, Mclnnes E, Mays N, Young J, Haines M. The effectiveness of clinical networks in improving quality of care and patient outcomes: a systematic review of quantitative and qualitative studies. BMC Health Serv Res 2016;16:360. doi: 10.1186/s12913-016-1615-z pmid: 27613378

10 Pettigrew LM, Kumpunen S, Rosen R, Posaner R, Mays N. Lessons for “large-scale” general practice provider organisations in England from other inter-organisational healthcare collaborations. Health Policy 2019;123:51-61. doi: 10.1016/j.healthpol.2018.10.017 pmid: 30509873

11 Ferlie E, Fitzgerald L, McGivern G, Dopson S, Exworthy M. Networks in health care: a comparative study of their management, impact and performance. Report for the National Institute for Health Research Service Delivery and Organisation Programme, 2010.

12 NHS England. Letter to the BMA General Practitioners Committee. Network contract DES2020/21, 20 May 2020. https://www.worcsImc.co.uk/cache/downloads/2020-05-20-PCN-DES-letter-toGPC.pdf

13 Baylis A, Perks-Baker S. Enhanced health in care homes. Learning from experience so far. King's Fund, 2017.

14 Pearce C. Nearly all GP practices sign up to primary care network DES. Pulse 2020 Jun 15. http://www.pulsetoday.co.uk/news/nearly-all-gp-practices-sign-up-to-primary-care-networkdes/20040997.article

15 NHS Confederation. Primary care networks: One year on. NHS Confederation, 2019.

16 Health Education England. Primary and community care training hubs. 2020. https://www.hee.nhs.uk/our-work/training-hubs.

17 British Medical Association. Focus-on: CCG mergers. 2019. https://www.bma.org.uk/media/1983/bma-ccg-merger-guidance-jan-2020.pdf

18 Pett W. Equipped for success? What clinical directors need for effective primary care networks. NHS Confederation, 2020. https://www.nhsconfed.org/resources/2020/01/pcns-equipped-forsuccess

This article is made freely available for use in accordance with BMJ's website terms and conditions for the duration of the covid-19 pandemic or until otherwise determined by BMJ. You may use, download and print the article for any lawful, non-commercial purpose (including text and data mining) provided that all copyright notices and trade marks are retained. 